\title{
EXPERIÊNCIAS DE CARDIOPATAS SUBMETIDOS À CIRURGIA CARDÍACA: UM ESTUDO EXPLORATÓRIO
}

\author{
Experiences of cardiopaths submitted to cardiac surgery: an exploratory study
}

Experiencias de cardiopatas sometidos a la cirugía cardíaca: estudio exploratório

CARolina Soraggi FreZ

EMma Elisa CARNeiro de CASTRO

\begin{abstract}
Resumo: Os objetivos deste estudo foram investigar e descrever os significados atribuídos às experiências de cardiopatas que se submeteram à cirurgia cardíaca, utilizando como base teórica a Gestalt-terapia. Cinco pacientes pós-operatórios foram entrevistados, sendo uma mulher e quatro homens, idades entre 52 e 65 anos, casados, autodeclarados brancos e pardos, escolaridade entre os níveis fundamental e médio. A análise dos dados foi realizada através da análise de conteúdo temática. Os resultados evidenciam que os principais significados atribuídos à experiência de cirurgia cardíaca se referem a ameaça à sobrevivência, perda do controle sobre si mesmos, perda da autonomia e da independência. $\mathrm{O}$ processo cirúrgico demanda um constante trabalho do sistema de orientação dos pacientes para que haja a manutenção da homeostase no organismo, havendo uma diversidade de reações regulatórias individuais que contribuem para a restauração do equilíbrio no meio em que se encontram.
\end{abstract}

Palavras-chave: Cirurgia cardíaca; Psicologia; Gestalt-terapia.

\begin{abstract}
This paper aims to investigate and describe significations of the experience of cardiopaths who were submitted to cardiac surgery, using the Gestalt-therapy as theoretical basis. The sample was composed by five post surgical pacientes, one woman and four men, ageing between 52 and 65 years old, married, self-declared white and brown, with scholarly between fundamental and medium levels. After the semiestructered intervieweds were done, the data was analysed through the tematic content analysis. The results of this study expose that the main significations related to the cardiac surgery refer to the threat to surviving, lost of control over yourself, lost of authonomy and independence. The surgical process demands a constant work of the pacient orientation system in order to exist the maintenance of the homeostasis in the organism, existing a diversity of individual regulatory reactions which contributes for the restauration of the balance of the environment in which they are located.
\end{abstract}

Keywords: Cardiac surgery; Psychology; Gestalt-therapy.

Resumen: Los objetivos de este estudio fueron investigar y describir los significados asignados a las experiencias de cardiopatas que se sometieron a la cirugía cardíaca, utilizando como base teórica la Gestalt-terapia. Cinco pacientes de postoperatorio fueron entrevistados, siendo una mujer y cuatro hombres, edades entre 52 y 65 años, casados, etnias blanca y parda, escolaridad entre los niveles fundamental y medio. Los resultados evidencian que los principales significados asignados a la experiencia de cirugía cardíaca se refieren a la amenaza de supervivencia, pérdida del control sobre sí mismos, pérdida de la autonomía y de la independencia. El proceso quirúrgico demanda un trabajo constante del sistema de orientación de los pacientes para que haya el mantenimiento de la homeostasis en el organismo, habiendo una diversidad de reacciones regulatorias individuales que contribuyen para el restablecimiento del equilibrio en el ambiente que se encuentran.

Palabras clave: Cirugía cardíaca; Psicología; La terapia Gestalt. 


\section{Introdução}

As doenças cardiovasculares constituem a maior causa de mortalidade no Brasil e no mundo. De forma a contribuir para a diminuição das taxas de morbimortalidade, as cirurgias cardíacas vêm sendo realizadas desde a década de 1950 e hoje são praticadas na maior parte dos estados brasileiros. Percebe-se que a cardiologia intervencionista se encontra em constante evolução, buscando o aperfeiçoamento das práticas, a diminuição dos riscos e a melhora da qualidade de vida para o paciente cardiopata (Hoffmann, Oliveira \& Massimi, 2014; Oliveira \& Oliveira, 2010; Takiuti et al., 2007). Mas, apesar do desenvolvimento técnico e científico, os pacientes que se submetem à cirurgia cardíaca continuam apresentando dificuldades tanto no enfrentamento do processo cirúrgico quanto na readaptação após a cirurgia, tendo repercussões nos âmbitos psicológico, comportamental e social.

Embora seja uma proposta para promover a cura ou melhorar a qualidade de vida, a cirurgia cardíaca é concebida como uma experiência limítrofe que pode preservar ou extinguir a vida, mobilizando fantasias e concepções individuais sobre o próprio indivíduo e sua subjetividade. Dessa forma, a experiência cirúrgica frequentemente é acompanhada por reações emocionais; como medo, ansiedade, angústia; assim como alterações da sensopercepção, do sono e do juízo de realidade (Bergvik, Sorlie \& Wynn, 2010; Oliveira \& Oliveira, 2010; Erdmann, Lanzoni, Callegaro, Baggio \& Koerich, 2013). Estudos como o de Wottrich, Quintana, Camargo, Quadros e Naujorks (2013), apontam que as vivências dos pacientes em preparação cirúrgica são compostas por sentimentos de imprevisibilidade sobre o futuro, falta de controle sobre a própria vida (despersonalização), vulnerabilidade, expectativa de ruptura da própria integridade e aproximação da morte. Além disso, a preocupação sobre o desempenho nas atividades de vida diária e a capacidade de retornar ao trabalho após o procedimento também são descritas pelos pacientes, interferindo na maneira como irão reagir durante o processo cirúrgico (Bergvik et al., 2010; Souza, Mantovani \& Labronici, 2006).

Tendo em vista que o processo cirúrgico abarca as vivências do pré, trans e pós-operatório, e que no transoperatório o paciente se encontra sob sedação, considera-se importante explicitar também as implicações no pós-operatório. De acordo com Banner (2010) e Lanzoni, Higashi, Koerich, Erdmann e Baggio (2015), o corte cirúrgico é descrito pelos pacientes pós-operatórios como uma forma de violação do corpo, podendo representar o rompimento de sua integridade. Percebe-se ainda que na unidade de terapia intensiva, onde eles acordam após o procedimento, acentua-se a desorganização psíquica. No estudo realizado por Wottrich, Quintana, Moré e Oliveira (2016), os pa- cientes descrevem sensações de desapropriação do próprio corpo e percepção de estarem em um ambiente assustador ao acordarem. Portanto, a experiência no pós-operatório imediato pode ser caracterizada pela limitação da autonomia e pelo desconhecimento de si mesmos, atribuindo à cirurgia cardíaca o sentido de impotência e finitude humana (Wottrich et al., 2016).

Jung (1978) afirma que o significado simbólico do coração como o centro da vida e dos sentimentos influencia na maneira das pessoas experienciarem os acontecimentos. Portanto, assim como as doenças do coração geralmente causam grande impacto emocional nos pacientes, observa-se que este aspecto se intensifica sobre aqueles que se submetem a uma cirurgia cardíaca, independente da faixa etária, sexo ou condição socioeconômica em que se encontram (Dórea \& Lopes, 2010; Oliveira \& Oliveira, 2010; Oliveira \& Lemos da Luz, 2009; Souza \& Ribeiro, 2010). Dessa forma, as cirurgias cardíacas têm significações diferentes em comparação ao tratamento realizado em outros órgãos, podendo a experiência do paciente ser influenciada não só pela historicidade de suas vivências, mas também pela representação de ameaça à vida e aos sentimentos.

A Gestalt-terapia, abordagem psicológica de caráter holístico e organísmico, contribui para a compreensão dos aspectos psíquicos envolvidos no processo de enfrentamento do adoecer e do tratamento. Diferente da visão biomédica que conceitua saúde como ausência de doença, para esta abordagem a saúde e a doença não são excludentes, mas se articulam em uma relação processual (Freitas, Stroiek \& Botin, 2010). Entende-se que a existência humana acontece a partir da interação da pessoa com o meio, considerando os processos sociais, físicos e psíquicos para compreender as experiências (Ginger \& Ginger, 1995; Perls, Hefferline \& Goodman, 1997). Dessa forma, o ser humano é visto como uma totalidade, em que o organismo e o meio interagem e mantêm uma relação de reciprocidade e interdependência (Perls, 1988).

Perls (1988) explica que a interação pessoa-meio ocorre através do processo de autorregulação organísmica, em que o estado de equilíbrio saudável (homeostase) depende do alcance contínuo de satisfação das necessidades. Neste campo interacional, formam-se as experiências humanas. Portanto, quando no campo interacional a pessoa se depara com algo que representa um risco ou ameaça para a integridade física e psicológica, há um impasse existencial ou experiência traumática (Melo, 2007). Esta experiência é vivenciada como sendo ao mesmo tempo intolerável e inevitável. Nestas circunstâncias, a pessoa imediatamente aciona as formas possíveis de lidar com a situação (Ribeiro, 1997), utilizando-se de ajustamentos criativos na tentativa de retorno ao estado de equilíbrio saudável. 
O ajustamento criativo representa o processo dinâmico e ativo de interação do indivíduo com o ambiente para solucionar situações e restaurar a harmonia, o equilíbrio, a saúde do organismo, o qual se dá por meio da autorregulação (processo espontâneo e inato em nosso organismo), que visa à satisfação das necessidades primordiais do momento, considerando as possibilidades ambientais (Antony, 2009, p. 357).

Tendo em vista que a manifestação de uma doença ou evento que ameace a vida, interfere no dinamismo e desenvolvimento, refletindo na desarmonização da pessoa (Chiattone \& Sebastiani, 1997), acredita-se que o processo cirúrgico gera um estado de crise que interfere na homeostase do paciente cardiopata, influenciando na expectativa de vida longa. Apesar da existência de estudos consistentes que confirmam as repercussões emocionais das cirurgias cardíacas durante o processo cirúrgico, pouco se sabe sobre como o processo de autorregulação acontece nessas situações. Dessa forma, os objetivos deste estudo foram investigar e descrever os significados atribuídos às experiências de cardiopatas que se submeteram à cirurgia cardíaca, utilizando como base teórica a Gestalt-terapia.

O interesse por este tema surgiu a partir do trabalho como psicóloga residente na equipe de cardiologia de um hospital público de ensino. Percebeu-se que os pacientes com proposta ou submetidos previamente à cirurgia cardíaca expressavam ansiedade, medo, angústia, e apresentavam dificuldade em aceitar novas propostas de cirurgias. O conceito de autorregulação advindo da teoria organísmica de Kurt Goldstein, que fundamenta a Gestalt-terapia, proporciona uma compreensão mais aprofundada desses fenômenos, sendo possível apreender sobre a complexidade das experiências desses pacientes.

\section{Metodologia}

\section{Participantes}

O estudo caracteriza-se como qualitativo e exploratório. Os participantes foram recrutados em um hospital universitário, localizado na região Sudeste do país. Considerou-se como critérios de inclusão: cardiopatas congênitos ou adquiridos acompanhados pela equipe de Cardiologia, com histórico de pelo menos uma cirurgia de revascularização miocárdica (CRVM) ou troca valvar realizada entre outubro de 2017 e outubro de 2018, com idade entre 40 e 65 anos, de ambos os sexos. A redução do intervalo de idade para 40 e 65 anos foi importante para caracterizar as experiências dessa faixa etária. Presume-se que ambas as cirurgias destacadas envolvem procedimentos operatórios e repercussões comuns, como a utilização de anestesia geral, a realização de esternotomia (incisão no músculo esterno), circulação extracorpórea, a permanência em unidade de terapia intensiva e o período de readaptação de doze meses a uma nova rotina (Romano, 2001). Como critérios de exclusão, considerou-se: pacientes com histórico de limitações cognitivas e dificuldades de comunicação verbal que impossibilitassem a participação na entrevista.

Dez pacientes foram convidados a participar do estudo e seis aceitaram o convite. Contudo, um dos entrevistados desistiu da participação após a realização da coleta dos dados por ter ficado desconfortável em relação ao próprio relato. Dessa forma, a amostra foi composta por cinco pacientes, uma mulher e quatro homens, idades entre 52 e 65 anos, casados, etnias branca e parda, escolaridade entre os níveis fundamental e médio. Os participantes realizaram a cirurgia cardíaca entre três e quatro meses antes da entrevista acontecer. Dois foram submetidos à CRVM após hospitalização por Infarto Agudo do Miocárdio (IAM) e três foram submetidos à cirurgia de troca valvar programada durante acompanhamento ambulatorial prévio.

A quantidade de participantes não foi definida a priori. A coleta de dados cessou após a ocorrência de saturação teórica, já que, desde o início do processo, foi realizada uma categorização contínua dos discursos, até que nenhuma nova categoria relevante para os objetivos desse estudo fosse constatada (Fontanella, Ricas \& Turato, 2008). A pesquisa atentou-se para as questões éticas, sendo aprovada pelo Comitê de Ética da Universidade Federal de Minas Gerais - UFMG (CAAE No 87598318.1.0000.5292.).

\section{Instrumentos e procedimentos}

Os instrumentos abrangem o sistema eletrônico do hospital, que proporciona os principais dados clínicos do paciente, um questionário fechado e uma entrevista semiestruturada (Figura 1), sendo os dois últimos elaborados pela pesquisadora. $\mathrm{O}$ questionário fornece subsídios para a caracterização socioeconômica, assim como, informações sobre o tratamento. A entrevista foi direcionada por um roteiro semiestruturado com questões que permitem o acesso às informações sobre as experiências dos pacientes. Realizou-se uma entrevista piloto com a finalidade de validar o roteiro elaborado.

As entrevistas ocorreram em local reservado dentro do hospital após os participantes terem consentido com a participação através do Termo de Consentimento Livre e Esclarecido (TCLE). O conteúdo foi gravado por um gravador eletrônico e, posteriormente, transcrito para a realização da análise. Considerando o risco de as entrevistas suscitarem mobilização emocional nos participantes, o suporte psicológico foi ofertado a todos os entrevistados. Somente o paciente que desistiu da participação no estudo aceitou o acompanhamento psicológico. Os participantes foram identificados pelas letras $\mathrm{M}$ ou $\mathrm{F}$ (masculino ou feminino), seguidos de um número sequencial que indica a ordem de realização das entrevistas, da idade e do tipo de cirurgia cardíaca realizada. 
1 Descreva a sua experiência de realização de cirurgia cardíaca, considerando desde o período pré-operatório até o pós-operatório.

2 Como você sentiu que a equipe de saúde te acompanhou durante o processo de tratamento cirúrgico? E como você imaginou que seria?

3 Alguma lembrança ou sentimento em relação à cirurgia já se repetiu em sua mente? Se sim, com que frequência? Descreva-a.

Figura 1. Roteiro de entrevista semiestruturada.

\section{Análise dos dados}

Utilizou-se a análise de conteúdo temática proposta por Bardin (1977). Cumprindo-se as seguintes etapas: pré-análise, exploração do material, tratamento dos resultados e interpretação. Na primeira, fez-se uma leitura flutuante dos relatos e, em seguida, desenvolveu-se hipóteses que auxiliaram na elaboração de unidades de significação. Posteriormente, foi realizada a edição das entrevistas, agrupando os textos em trechos que teorizam uma ideia em comum. Na terceira etapa ocorreu um processo de reflexão e intuição a partir do embasamento teórico escolhido para este estudo. A relação entre os dados obtidos e a fundamentação teórica auxiliou a dar sentido às interpretações (Bardin, 2009).

\section{Resultados e discussão}

A partir das narrativas dos participantes, foram formulados núcleos de sentido de onde emergiram as seguintes categorias e subcategorias de significações:

$>$ A preparação e o momento da cirurgia: os sentidos da cirurgia cardíaca.

- O medo, a percepção de risco de vida e a perda de controle.

- Expectativas e construção da confiança.

$>$ O pós-operatório imediato: da dependência à independência.

-A vivência na Unidade Coronariana (UCO): percepções do ambiente e de si.

• Recuperação: o retorno à independência.

\section{A preparação e o momento da cirur-} gia: os sentidos da cirurgia cardíaca O medo, a percepção de risco de vida e a perda de controle.

Em geral, a proposta cirúrgica incita a percepção de risco de vida no paciente, sendo acompanha- da por sentimentos de ameaça e medo. No conjunto de narrativas, somente um dos participantes relata ter ficado tranquilo nessa fase do processo. Os sentidos em torno dos quais os depoimentos giram - risco e sensação de perda de controle sobre a própria vida - apontam para a percepção de que a cirurgia cardíaca representa uma ameaça para a integridade física e psicológica, ou a possibilidade de finitude da vida: Eu tinha medo de morrer numa mesa de cirurgia... o antes é muito ruim. Que a gente fica... sei lá... com muito medo e tudo. (...) E eu: não doutor, posso morrer, eu não quero. (...) Não queria de jeito nenhum operar. (F-1, 62, troca valvar)

Aí minha casa caiu né, perdi o chão (...) naquele momento eu tomei aquele choque... [momento em que a cirurgia foi indicada]. (M-2, 52, CRVM)

Muita fé em Deus, eu permanentemente acho que quando tava consciente no hospital rezava muito e dizia a Deus que se era minha hora de ir embora que Ele tinha que me levar e se não fosse, que Ele tinha que me recuperar (M-4, 64, CRVM)

No início quando eu soube que eu tinha que fazer uma cirurgia, no início eu fiquei um pouco com medo né, porque eu pensei assim: nossa, eu vou correr um risco, né. (M-5, 59, troca valvar)

De forma semelhante, o momento em que o paciente é direcionado para o bloco cirúrgico é vivenciado de forma insegura por aproximar-se da situação ameaçadora. Dentre os participantes, três se referiram à vivência no bloco cirúrgico ou ao momento da cirurgia. Percebe-se que diferentemente da fase anterior, em que a ameaça é longínqua, os sentidos que as narrativas apresentam sobre o momento da cirur- 
gia são de uma aproximação da morte, ameaça real e imediata à sobrevivência. Oliveira e Lemos da Luz (2009) explicam que como a cirurgia cardíaca simbolicamente representa interferência no centro da vida e das emoções, do ponto de vista individual de quem opera o coração é sempre tudo ou nada, pouco importando que a maioria das pessoas tenham se saído bem. Como explicitado nas narrativas seguintes:

Quando a minha menina me contou: mãe, você parou numa mesa de cirurgia. Eu falei: nó, então eu morri! E vivi de novo. Ela falou: isso aí. E se eu não tivesse voltado?

(Os médicos) falaram pra mim que é uma cirurgia perigosa. Muito. Que eu poderia morrer sim. (F-1, 62, troca valvar)

Quando eu cheguei no bloco cirúrgico, aí que eu... que caiu a ficha que eu vi que o trem era sério mesmo. (...) Conversei com o anestesista lá dois minutos, falei com ele: ô cara, cê tá me apagando, mas cê me faz voltar. (...) Porque eu sempre tive pavor com relação a cirurgia. Eu nunca fiz cirurgia, ainda vai fazer logo uma de coração, peito aberto... O coração não é coisa que brinca né. (M-2, 52, CRVM)

Que a gente assina um termo [termo de consentimento], né! Porque tudo pode acontecer né. (...) Que se ocê lembrar do que cê passou, do risco que tem né. (M-5, 59, troca valvar)

Esses resultados são consonantes com estudos da literatura que demonstram que o medo é um dos sentimentos mais comuns nos cardiopatas cirúrgicos (Erdmann et al., 2013; Roohafza et al., 2015; Wottrich et al., 2013; Wottrich et al., 2016), tanto em relação à percepção de ameaça a vida no pré-operatório, como diante da vivência de perda de controle durante o transoperatório. Ao se submeter à anestesia, o paciente entrega-se nas mãos da equipe médica, havendo a perda da autonomia e do poder de decisão sobre si mesmo (Wottrich et al., 2016). De acordo com Oliveira e Lemos da luz (2009), o temor demonstrado pelos pacientes no bloco cirúrgico está associado tanto ao receio de não acordar quanto ao fato de serem manipulados sem que possam participar. Percebe-se que neste estudo, as narrativas em relação ao momento da cirurgia também giram em torno da vivência de submissão à equipe e da pouca participação ativa do paciente. Destaca-se uma das falas que representa a insegurança de M-2 ao se perceber sem o controle da situação e sem o poder sobre si mesmo:

Porque quando você tá fazendo uma coisa que você conhece, que você está fazendo, você sabe se vai ficar bom, se não vai... é uma coisa. Quando você tem uma outra pessoa fazendo uma coi- sa que vai definir os rumos da sua vida... é preocupante. Cê não sabe se o cara acordou bem, se ele tá fazendo bem feito, se ele fez certinho... rola essas dúvidas: será que ficou bom?; ah, será que esse trem vai dar certo; será que vai ter perigo, será que não tem. (52, CRVM)

Percebe-se que tanto a hospitalização como a intervenção cirúrgica contribuem para a vivência de despersonalização, caracterizada pela impossibilidade de o sujeito ser agente de si mesmo, e para o desencadeamento do sentimento de impotência (Ai, Peterson, Tice, Bolling \& Koening, 2004; Wottrich et al., 2016). Dessa forma, ao se perceber em um contexto que acentua a postura de passividade, o sujeito se depara com a impossibilidade de ser agente das decisões e ações sobre o próprio corpo. Ao descrever a vivência no bloco cirúrgico, M-5 ressalta a atividade de outros sobre ele mesmo, colocando-se passivamente na situação:

Lembro. Cheguei lá. Eles me pegaram lá puseram o roupão lá e levaram cheguei lá no bloco havia bastante gente lá eu nem sei... só sei que tinha muito assim em volta lá. Aí eles me colocaram lá... aí cada um pega em você, pega num braço, pega no outro braço. Coloca um negócio ali, um negócio dali. Aí eles falaram comigo assim: agora nós vamos colocar uma máscara e você respira, estava saindo tipo uma fumacinha assim, e você respira isso aí. Aí eles colocaram a máscara né, e eu comecei respirando e depois não vi mais nada, quando eu acordei eu já estava descendo para a UTI, né? (59, troca valvar)

De acordo com Perls (1988), o processo de autorregulação opera a serviço da sobrevivência do indivíduo no âmbito da vida e da morte. Dessa forma, quando dentro do campo pessoa-meio surge uma situação que representa risco ou ameaça para a integridade, como a cirurgia cardíaca, o processo homeostático falha e a pessoa imediatamente aciona formas rápidas e econômicas de lidar com a situação (Ribeiro, 1997). Isso acontece, como explica Kurt Lewin através da Teoria de Campo, porque o ser humano é produto do meio em que se encontra e da energia que possui em determinado momento, assim, o comportamento humano deriva da inter-relação dos fatos coexistentes no presente.

Percebe-se que ao representarem a cirurgia cardíaca como ameaça à sobrevivência e perda de controle sobre si mesmos, os pacientes geralmente respondem com medo e insegurança. Essas respostas aparecem como ajustamentos criativos para neutralizar a angústia diante de um campo com características ameaçadoras, como o hospital e a cirurgia cardíaca, sinalizando que uma necessidade importante está insatisfeita e, por consequência, uma Gestalt está aberta (Antony, 2009). 
Perls (1988) define Gestalt como um todo, um complexo em si, que tem uma dinâmica reguladora de toda a vida orgânica. O autor explica que quando uma necessidade não é atendida, uma Gestalt é desfeita, tornando-se partículas ou situação inacabada que precisa ser completada. Contudo, para que a Gestalt se complete, é necessário que a pessoa se dê conta (dar-se conta) da necessidade insatisfeita, sendo propulsora de sua própria satisfação para que possa continuar (Perls, 1988) a dinâmica da vida.

Portanto, quando os pacientes pré-operatórios percebem que a necessidade de sobrevivência está ameaçada, permitindo-se entrar em contato com o medo e a insegurança, estas reações se tornam energias cooperativas. Durante este processo, o paciente se encontra em uma fase transitória, em que o medo através da suspeita se transforma em experimentação, ou seja, ampliação das órbitas da vida (Perls, 1977b), ofertando novos sentidos à existência.

Tendo como pressuposto que o processo de autorregulação envolve a participação ativa da pessoa no meio, as vivências do medo e da insegurança parecem impulsionar o posicionamento ativo a favor da satisfação da necessidade de sobrevivência. Esse aspecto pode ser observado nos exemplos acima, quando os participantes descrevem ter respondido aos proponentes posicionando-se contra a proposta cirúrgica, ou solicitando que o médico não deixe de fazê-los voltar a vida, ou mesmo utilizando-se da fé religiosa como forma de suporte.

Perls et al. (1997) ressaltam que mesmo em situações objetivamente imutáveis, emergem reações regulatórias do organismo que contribuem para a restauração do equilíbrio, desde que a pessoa permita a expressão das reações corporais e emocionais. Ressalta-se, portanto, que a ocorrência das respostas de medo e insegurança não implicam em si um ajustamento disfuncional (Aguiar, 2014), mas ao contrário, quando experimentadas pelo sujeito visam à satisfação das necessidades e se configuram em formas saudáveis de enfrentar a situação.

Os exemplos desta subcategoria revelam dinâmicas psicológicas individuais tentando se organizar criativamente para manter a saúde psíquica (Antony, 2009) diante da situação de ameaça. Perls (1988) aponta que as necessidades de sobreviver e de crescer agem como força propulsora em todos os seres vivos, tornando-se figura enquanto as outras necessidades recuam, pelo menos temporariamente, para o segundo plano. Dessa forma, para que o paciente cardíaco, o qual se vê ameaçado tanto por ter uma doença no órgão que representa a vida quanto porque a proposta de tratamento possui características de risco, satisfaça a necessidade de preservação da vida e feche a Gestalt, faz-se importante sentir-se participante em relação a si próprio e ao meio em que se encontra.

\section{Expectativas e construção da confiança}

Enquanto a percepção de aproximação da morte e a vivência de submissão ao outro são acompanhadas por medo e insegurança, os depoimentos sobre o momento da cirurgia apresentam-se também permeados por expectativas de sucesso e confiança. Percebe-se, portanto, que o processo de aceitação da proposta cirúrgica no período pré-operatório envolve sentimentos antagônicos (Wottrich et al., 2016) que contribuem de forma adaptativa para o enfrentamento da situação.

Então agora eu fui pra mesa [mesa de cirurgia] sorrindo, maquiada, bem bonita e convicta de que eu ia sair bem da cirurgia. E saí. Né? (F-1, 62 , troca valvar)

Eu sabia o quê que tava acontecendo, qual o processo que eu iria passar (...) então eu fui bem consciente, sabe, bem consciente, bem esclarecido pra essa cirurgia. (M-3, 65, troca valvar)

E quando chegou a cirurgia mesmo eu já tava muito confiante que ia dar tudo certo. (...) e daí para frente fui pegando mais confiança né. Quando chegou o dia da cirurgia mesmo nem estava com medo mais não. Eu sabia que ia dar certo. (...) eu tava bem confiante que ia dar certo. (M-5, 59, troca valvar)

Diante da manifestação de medo e de insegurança por parte do paciente, alguns aspectos parecem favorecer a construção da confiança no processo cirúrgico. Em geral, o suporte ofertado pela equipe de saúde, a assistência atenta às necessidades dos pacientes durante o período preparatório e a percepção positiva que os pacientes têm sobre os profissionais e a instituição auxiliam na construção de expectativas positivas acerca da cirurgia cardíaca. Os estudos de Banner, Miers, Clarke e Albarran (2012), Erdmann et al. (2013) e Wottrich et al. (2013) confirmam que o sentimento de esperança apresentado por esses pacientes também está relacionado à perspectiva de um futuro sem dor, com mais capacidade para o trabalho e melhor qualidade de vida.

No conjunto de narrativas deste estudo, os pacientes que receberam preparação ambulatorial para a realização da cirurgia de troca valvar mostram-se mais confiantes e ressaltam a importância do suporte ofertado pela equipe de saúde antes da hospitalização. O mesmo não foi observado nos depoimentos dos pacientes que realizaram a cirurgia de revascularização miocárdica após a ocorrência de IAM. Esse é um aspecto que diferencia as experiências dos cardiopatas cirúrgicos. Enquanto os primeiros têm a oportunidade e o tempo de trabalharem os medos e inseguranças com o auxílio da equipe ambulatorial, os pacientes que são acometidos pelo IAM e necessitam da cirurgia de revascularização miocárdica de 
urgência se deparam com duas ameaças significativas em um curto período de tempo, não recebendo o mesmo suporte para auxiliar no enfrentamento das vivências de risco.

Oliveira e Lemos da Luz (2009) concordam que na cirurgia eletiva o paciente pode ser melhor preparado em relação à de urgência, tanto do ponto de vista físico como psicológico. A partir do momento em que se informa ao paciente a situação pela qual irá passar, aumenta seu controle sobre ela e isso ajuda a diminuir a ansiedade. As narrativas seguintes apontam a importância da preparação acompanhada, vivenciada pelos pacientes que realizaram a cirurgia de troca valvar. A partir do suporte ofertado pela equipe, eles se mostram mais confiantes, com menos medo e menos vulneráveis.

Nas consultas que eu tive aqui. Só que os médicos foram, né, conversando comigo: cê pode, a senhora dá conta, a senhora é jovem. (...) Os médicos que me animaram. E elas [as fisioterapeutas] me falaram antes: (...) a senhora pode ter certeza. Estou te dando a minha palavra. A senhora não vai acordar sozinha, o seu tubo [endotraqueal] não vai ser demorado para tirar e a gente vai tá lá. (F-1, 62, troca valvar)

[A cirurgia] foi uma coisa programada, acompanhada, conversada, muito bem conversada com a Doutora X. (...) com todo o acompanhamento, com todo esclarecimento, inclusive.

Antes, inclusive, eu tive uma moça aqui do hospital que me atendeu falando tudo a respeito da cirurgia, como é que seria, quais que seriam os procedimentos, pós-cirúrgico como que eu teria que ter agido até pra tossir, ou movimentar os braços, né, pra que não houvesse um problema maior. (...) então eu fui bem preparado psicologicamente, fui bem preparado sabe?! (...) às vezes se tivesse sido uma coisa assim de relance, de ter acontecido um problema maior, de eu ter que passar por isso, talvez eu cairia numa situação depressiva, uma coisa assim mais né, poderia me trazer uma coisinha assim mais né. (M-3, 65, troca valvar)

Comecei consultando com os médicos daqui. Foi com o Doutor Y né, com os residentes ... aí eu fui, eles foram me explicando né, como que ia ser a cirurgia, aí eu fui perdendo aquele medo né, pegando aquela confiança. (M-5, 59, troca valvar)

Percebe-se que a relação do paciente com os profissionais e a instituição também é um fator importante para a construção da confiança no processo cirúrgico. Somente um dos participantes não fez referência à percepção que tinha da instituição e da equipe. As demais narrativas demonstram que as percepções positivas sobre os profissionais e sobre o hospital desde o período anterior à cirurgia, contribuem para a existência de tranquilidade diante do procedimento. Dessa forma, tanto a preparação ambulatorial quanto a relação positiva entre paciente e profissionais, parecem contribuir de forma adaptativa para o enfrentamento da cirurgia cardíaca. Reconhece-se, portanto, que a partir do encontro entre profissionais e pacientes no aqui e agora das experiências, acontecem os processos de construção do planejamento, da esperança e da previsibilidade sobre o futuro (Perls, 1977b).

Amo, amo vim consultar aqui. Gosto muito! (F1,62 , troca valvar)

Olha, eu já tive outra experiência no hospital, tá entendendo (...), então eu já conhecia isso aqui e eu tenho um grande apreço por esse hospital, exatamente por causa desse atendimento... eu procuro fazer tudo por aqui, porque eu sei que aqui além de ser um hospital-escola, são excelentes profissionais, em todas as áreas, cê tá entendendo... tanto médico, quanto iniciantes, quanto hospital, eu realmente gosto demais daqui, em termos de hospital.

[não senti medo] porque sabia que estava num lugar bom, com profissionais de qualificação boa, e num lugar que tinha que procurar uma solução adequada pra mim. (M-4, 64, CRVM)

Eu falei assim, ah, eu pensei assim: estou em boas mãos aqui. Eu escolhi aqui, o hospital né. E aí tem o Dr. H também nessa história. (...) de cara me falaram que ele era um bom cirurgião: que você vai estar em boas mãos. Então eu tive toda confiança. (M-5, 59, troca valvar)

Mello e Burd (2004) defendem que a proposta cirúrgica sempre é apreendida como uma urgência, a qual o paciente responde reunindo todos os esforços possíveis para responder à situação. Assim, a partir do sistema de orientação presente no organismo, a pessoa se torna capaz de identificar quais os objetos externos satisfarão suas necessidades. Segundo Perls (1988), uma vez que o sistema de orientação identifique os objetos necessários, a pessoa contata com seu meio, tornando-se capaz de manipulá-los e de reinstaurar o equilíbrio orgânico. $\mathrm{O}$ autor explica que:

As emoções são a própria linguagem do organismo; modificam a excitação básica de acordo com a situação que é encontrada. A excitação é transformada em emoções específicas e as emoções são transformadas em ações sensoriais e motoras. As emoções energizam as catexis e mobilizam os modos e meios de satisfação das necessidades. (Perls, 1988, p. 37)

Essa dinâmica de autorregulação acontece porque o ser humano é uma totalidade que se desenvolve através da relação ativa e ininterrupta com as forças do campo no qual interage, sendo ao mesmo 
tempo singular, ser de relação e ser-no-mundo, em contato contínuo com a realidade (Aguiar, 2014; Ribeiro, 1994). Portanto, a Gestalt somente ocorre com outras pessoas e para as outras pessoas, sendo essencial que haja relação para que ela aconteça (Perls, 1977b). Acredita-se que ao ofertar escuta atenta e assistência as necessidades dos pacientes, pode-se auxiliá-los na realização de ajustamentos criativos e, finalmente, no atravessamento do processo cirúrgico auxiliando na preservação da autenticidade do paciente.

Destaca-se que as ideias que remetem à construção de confiança - suporte da equipe e percepção positiva da instituição - se sobrepuseram aos aspectos que promoveram insegurança - percepção negativa da instituição e vivência cirúrgica anterior. Somente duas narrativas expressaram essas influências:

A primeira vez eu sofri muito. Não foi aqui, tá? Foi em outro hospital. Então eu acordei sozinha, foi muito pânico. Aqui eu não tive isso. (...) sabe, a primeira vez que eu operei eu senti muita sede, não aparecia ninguém. Eu tava amarrada... dessa vez eu não estava amarrada. Eu queria conversar, mas o tubo era muito grosso. Sabe? Ele tampava a minha boca toda. Eu não podia conversar. Não podia engolir saliva e as pessoas não chegavam perto de mim. Ninguém! Eu fiquei desesperada, sabe? Parecia que faltou ar em mim. (...) aí se fosse para passar a mesma coisa... (F-1, 62, troca valvar)

Eu não imaginei que fosse assim, porque a gente quando não está no hospital, você vê muita reclamação na televisão, dizendo que uma pessoa foi mal atendida, morreu na porta do hospital, que foi mal atendida, que... então eu não esperava que fosse tão bom o tratamento. (M-4, 64, CRVM)

Portanto, a partir da compreensão de que a cirurgia cardíaca é uma vivência complexa e que demanda um trabalho constante do sistema de orientação da pessoa, vê-se a importância de proporcionar aos pacientes a possibilidade de experimentação dos sentimentos presentes e auxiliá-los na compreensão dos significados desse processo (Rosário \& Esch, 2014). Assim como foi apontado nas narrativas, ao se sentirem acolhidos, amparados e acompanhados por bons profissionais, os pacientes se tornam mais confiantes e adquirem novas formas de enfrentar a situação. Essa perspectiva também é defendida por Carné (2002), ao explicar que o ato de acolher é compreendido como cuidar, amparar, acompanhar e respeitar, sendo a partir do acolhimento que nasce a confiança e, consequentemente, a entrega para vivenciar a situação com mais equilíbrio. Ou seja, ao realizar o acolhimento, possibilita-se a ampliação do campo interacional que o contexto hospitalar e de adoecimento tanto limita, ofertando espaço para a expressão das angústias e também para a ressignificação da experiência (Parreiras, 2017).

\section{0 pós-operatório imediato: da de- pendência à independência $A$ vivência na unidade coronariana (UCO): per- cepções do ambiente e de si}

O conjunto de significados atribuídos ao pós-operatório imediato, que ocorre na unidade de terapia intensiva coronariana, gira em torno da vivência de dor, do estranhamento com o próprio corpo e com o ambiente e da dependência para satisfazer as necessidades mais básicas dos pacientes. O único participante que não relatou esses significados ressaltou a importância da preparação realizada junto à equipe de saúde para que ele enfrentasse tranquilamente esse momento do processo. As narrativas seguintes exemplificam essas ideias:

Na UCO foi difícil! Por causa de barulho, de lâmpadas... né? E pessoas a noite toda. Quando cê acorda, toda... sozinha, querendo... engolindo saliva e não consegue... aquele tubo ridículo [tubo endotraqueal]! Sabe? (F-1, 62, troca valvar)

Só é um processo dolorido, cê não consegue mexer, pra você deslocar o corpo cê tem que pedir pra alguém e tal (...). Sabe? Precisa de mexer, tem que pedir alguém, aí alguém te levanta. Precisa de fazer xixi aí a pessoa te traz um marreco pra você: olha, to precisando de... Depende de todo pra tudo. (...) Entendeu. (...) Então é complicado por isso. (...) Porque, olha, os primeiros momentos depois da cirurgia são bem complicados. É bem, eu acho que... é bem debilitante. (M-2, 52, CRVM)

Ah, eu sentia que eu tinha muito medicamento no meu corpo, tanto é que eu olhava para as paredes e sentia tudo meio azul, eu olhava para uma parede branca e eu via a parede roxa, azul, um azul meio roxo nas paredes, não senti dor em momento nenhum, só as dores normais de uma injeção, minha barriga aumentou, era injeção todo dia e tal, mas eu sabia que era necessário, pro bem, né. (M-4, 64, CRVM)

Eu senti bastante dor. Assim, sentia, (...) dor eu senti mesmo, sabe, mas isso faz parte, né. Não tem jeito de não sentir dor, né. (...) A gente tá com um tanto de mangueira [drenos], né. Nossa era bem complicado, viu. A gente nem podia mexer direito, aparelho assim em todo canto, tinha bolsa, né, tinha uma sonda aqui que vinha aqui em cima [mostra o pescoço], essa doeu na hora de tirar, muito um tanto assim. Ai eu ... onde eles tinham colocado tinham colado, sabe, aí hora que tirou assim, saiu um tanto de sangue. 
Mas lá tinha que tomar banho de leito, eu tomei banho de leito lá. (...) Tomei banho de leito, vira para lá, vira pra cá. (M-5, 59, troca valvar)

Quando após a realização da cirurgia cardíaca o paciente sai do sono anestésico e toma consciência sobre si mesmo ligado às sondas, cateteres, drenos e sob efeito de diversos medicamentos, em um ambiente caracterizado por sons, cheiros, ruídos e movimentações incomuns, tende a interpretar a situação como assustadora (Erdmann et al., 2013; Lanzoni et al., 2015; Oliveira \& Lemos da Luz, 2009), sentindo-se dependente, debilitado e desamparado para enfrentá-la. A associação do estranhamento em relação ao ambiente e ao próprio corpo com a sensação de dependência devido à restrição ao leito, à utilização de instrumentos invasivos e à ocorrência de dor, parecem ser os aspectos que mais dificultam a adaptação do paciente ao novo momento do processo (Dutra \& Coelho, 2008; Erdmann et al., 2013; Lanzoni et al., 2015; Wottrich et al., 2016). Acredita-se que isso acontece porque durante o tempo de hospitalização e sobretudo na unidade de terapia intensiva, em que a angústia se torna mais presente devido à percepção de limite, a atenção se volta para o corpo, tornando-se figura para o paciente (Parreiras, 2017).

Polster e Polster (2001) explicam que no processo relacional da pessoa com o meio há uma fronteira de contato que corresponde ao encontro do organismo com o mundo externo e é através dela que a percepção da pessoa sobre a sua identidade se desenvolve. Para que haja contato, além do aspecto conservativo dos ajustamentos orgânicos é essencial que haja contato com o novo. Afinal, o organismo não pode se preservar sem assimilar alguma coisa do ambiente (Perls et al., 1997). Sabe-se que awareness é o processo de estar em contato vigilante com os eventos importantes do campo pessoa-meio, com total apoio sensório-motor, emocional, cognitivo e energético (Yontef, 1998). Portanto, estar aware requer autoconhecimento e conhecimento da situação atual. Por outro lado, quando alguma exigência da situação ou as necessidades da pessoa são negadas, como ocorre com os pacientes no pós-operatório imediato, ocorre uma perturbação da awareness.

No caso dos cardiopatas cirúrgicos, ao despertarem eles percebem que a autonomia sobre si mesmo e sobre o próprio corpo se encontra limitada, significando as vivências do pós-operatório imediato como provas da impotência e da finitude humana (Wottrich et al., 2016), havendo uma perturbação da awareness. Partindo da explicação de Yontef (1998), compreende-se que a ausência de awareness é o resultado do não estabelecimento de contato pleno entre a pessoa e o meio, seja devido ao fato de a pessoa estar imersa em seu próprio meio interno, seja pela falta de contato com a vida interior pela fixação com o que é externo. Dessa forma, o paciente que se encontra com a independência limitada por estar na unidade de terapia intensiva após a cirurgia cardíaca, vê-se impedido de realizar escolhas e movimentos espontâneos, permanecendo em constante tentativa de se ajustar à situação e de reestabelecer o equilíbrio.

\section{Recuperação: o retorno à independência}

Percebe-se que a passagem pela terapia intensiva após a cirurgia cardíaca é apreendida como uma experiência desafiadora e difícil (Erdmann et al., 2013; Lanzoni et al., 2015; Wottrich et al., 2016), principalmente quando o tempo de permanência é longo. A vivência do processo de recuperação, por vezes com presença de dor e necessitando do desenvolvimento constante de defesas autorregulatórias, pode acarretar tristeza, agitação e estados confusionais (Oliveira \& Lemos da Luz, 2009).

Um dos fatores que parece contribuir para a diminuição do sofrimento do paciente que se encontra na Unidade Coronariana (UCO), é a assistência rápida da equipe diante da percepção das necessidades do paciente. Três participantes ressaltaram a importância da prontidão dos profissionais para atenderem as suas demandas. Percebe-se que diante das limitações em que se encontra o sujeito, ele busca através do sistema de orientação e encontra novamente no meio os objetos para atendê-lo:

Fui muito bem cuidada aqui. (...) eu acho que eu tive tudo na hora certa de mais. (...) Quando eu acordei tinha médico perto de mim. Tinha enfermeira. Tinha um tanto de gente. Aí eu lembro quando eu abri os olhos das primeiras pessoas que eu vi. E tudo que eu pedi, até água que não pode né... molharam a minha boca com algodão... porque não podia beber água. Mas rapidinho tirou o tubo e liberou um pouquinho, aquele copinho menorzinho de café, meio copinho só. (F-1, 62, troca valvar)

Eu não esperava que fosse tão bom o tratamento, tão rápido, assim, em cima de um problema pra solucionar, independentemente de um aparelho estragado né (...) eu sinto o que tinha que ser feito, podia ser feito foi feito [refere-se à equipe de saúde]. (M-4, 64, CRVM)

Mas eles não deixavam [sentir dor] ... toda hora eles aplicavam um remédio em mim. Toda hora, toda hora. (...) Aí... lembro daquelas meninas ali tudo que aplicava o remédio em mim (...) e elas já tem a prática né de fazer tudo aquilo ali. (M-5, 59, troca valvar)

Nota-se que o curto período de permanência na UCO é outro fator que contribui para a diminuição do sofrimento no pós-operatório imediato. Os participantes interpretam que tiveram uma boa recuperação a partir da percepção de que foram transferidos com poucos dias da UCO para a enfermaria. As narrativas 
sobre a recuperação pós-operatória giram em torno do significado de retorno à independência. Geralmente, na enfermaria os pacientes já se encontram em condições de se levantar, realizar algumas atividades básicas sem auxílio, havendo percepção de retorno progressivo à independência. Somente M-5 relatou sofrimento durante o período que esteve na enfermaria, justamente por ainda não se perceber independente.

Foi difícil, mas eu fiquei bem (...) fiquei pouco tempo na UCO e fiquei pouco tempo aqui também. O meu problema maior aqui foi controlar o RNI [monitorização do anticoagulante]. É, eu fiquei ótima. Eu com três dias no quarto eu tomava banho sozinha. Precisava de acompanhante não. Então, foi isso. (F-1, 62, troca valvar)

Aí, aí foi tudo bem. (...) Eu fui conseguir levantar na terça feira, na segunda feira de madrugada eu levantei da cama e já conseguir levantar e tal. (M-2, 52, CRVM)

Fiquei em tratamento lá, de recuperação, lá na terapia intensiva e tal, até no dia que me liberaram, fui pra casa. (...) Fui ficando na mão de Deus, até que me recuperaram. (...) Então eu não esperava que fosse tão bom o tratamento, tão rápido. (M-4, 64, CRVM)

Só sei que a recuperação foi até boa, né. Aí com três dias já me tiraram [da UCO] e fui para enfermaria. (...) Mesmo na enfermaria, porque eu fiquei 16 dias internado, aí não podia nem mexer muito na cama né, quando eu levantava ficava tonto tinha que sentar rápido, para tomar banho minha esposa tinha que ir comigo, pra me segurar... (...) porque a gente... eu sofri bastante disso daí também. (M-5, 59, troca valvar)

Ginger e Ginger (1995) explicam que interrupções prolongadas e repetidas das ações das pessoas podem levar a consequências patológicas. Afinal, o sistema de inibição da ação que é acionado nos momentos em que as reações de fuga ou luta não são possíveis é destinado para funcionar apenas por períodos curtos, havendo desregulação dos neuromediadores caso seja exigido por períodos longos.

Apesar de os pacientes cirúrgicos acionarem o sistema de inibição da ação ao se depararem com os limites físicos e ambientais característicos do período pós-operatório imediato, este não se faz necessário por um período longo. Diante do retorno progressivo das atividades corporais, da retirada do tubo endotraqueal, dos drenos e cateteres e à medida que recobra a força muscular, sendo capaz de realizar as atividades básicas da vida diária, o paciente volta a realizar progressivamente respostas espontâneas, sentindo-se mais livre. Portanto, ao alcançar a satisfação das necessidades de forma dinâmica e por meio da homeostase, seja no âmbito fisiológico ou psicológico, os pacientes voltam a ser saudáveis.

Na perspectiva gestáltica, a saúde e a doença são conceitos dinâmicos, não polarizados, caracterizados pela interação, sendo formas de o organismo dar sentido à sua existência na busca de trocas constantes com o meio (Figueiredo \& Castro, 2015). O funcionamento não saudável ocorre na fronteira de contato e se refere à inabilidade de se relacionar criativamente com o meio, relacionando-se, ao invés disso, através de padrões cristalizados e repetitivos (Frazão, 1992). Perls afirma que:

o ser humano parece nascer com um sentido de equilíbrio social e psicológico tão acurado quanto seu sentido de equilíbrio físico. Cada movimento que faz no seu nível social ou psicológico é dirigido para a descoberta deste equilíbrio, de equilíbrio estável entre suas necessidades pessoais e as demandas de sua sociedade. (1977a, P. 41)

Portanto, em condições favoráveis os cardiopatas cirúrgicos se mostram capazes de buscar na relação com o meio a melhor configuração possível para realizar os ajustamentos criativos e chegar ao estado de equilíbrio, retornando ao funcionamento saudável. Nesta perspectiva, entende-se funcionamento saudável durante o período de recuperação como a busca por autonomia e pelo retorno à independência, como descrito por M-2:

Depois de um certo tempo a coisa vai amenizando, as dores vão passando e você começa a cair na sua rotina de novo e aí volta, vai voltando as coisas a ser como eram. Entendeu? É isso aí. (...) Isso foi um episódio que aconteceu. Eu tive um infarto, tive que fazer a cirurgia, e fiz a cirurgia e recuperei. (M-2, 52, CRVM)

A partir da percepção de boa recuperação e de retorno à vida, o paciente que realizou a cirurgia cardíaca se percebe como um ser de possibilidades, dotado de liberdade para escolher sua essência a cada instante, consumando, assim, seu projeto de vida e de se-no-mundo. De acordo com Cardoso (2017), o ser humano é concebido como abertura para o mundo, só se constituindo como pessoa enquanto está em conexão com ele, ou seja, é definido como um ser-em-relação. Assim, o processo de saúde se configura através da realização de ajustamentos criativos, ou seja, está relacionado à capacidade do ser humano se posicionar de forma criativa e autêntica no contexto em que se encontra, não excluindo as possibilidades e limites, mas reconhecendo e legitimando suas experiências (Cardoso, 2017).

\section{Considerações finais}

Os resultados deste estudo evidenciam que as experiências dos pacientes cardiopatas que se subme- 
tem à cirurgia cardíaca são permeadas pelos significados de ameaça à sobrevivência, perda do controle sobre si mesmos, perda da autonomia e da independência. Por ser composto pelos períodos pré, trans e pós-operatório e caracterizado por diversas situações que representam risco ou ameaça para a integridade física e psicológica, o processo cirúrgico demanda um constante trabalho do sistema de orientação dos pacientes para que haja a manutenção da homeostase no organismo. Percebe-se que mesmo havendo aspectos semelhantes entre as experiências dos pacientes, há uma diversidade de reações regulatórias individuais que contribuem para a restauração do equilíbrio no meio em que se encontram.

Ressalta-se que no caso dos pacientes que realizaram a cirurgia de troca valvar, a expressão das reações corporais e emocionais foram permitidas e acolhidas a partir do suporte ofertado pela equipe de saúde durante o pré e o pós-operatório, sendo trabalhadas de acordo com as possibilidades da situação em que se encontravam. Esse aspecto parece ter contribuído para a construção de expectativas positivas e da confiança acerca da cirurgia cardíaca, tendo auxiliado de forma adaptativa para o enfrentamento do processo cirúrgico e para a reinstalação da homeostase.

Os resultados refletem as experiências de um grupo pequeno de pacientes de meia idade. Sugere-se que pesquisas futuras sejam realizadas com pacientes de outras faixas etárias, caracterizando também as questões de gênero e etnia, de forma a apreender semelhanças e diferenças entre as populações. Além disso, faz-se necessário considerar as diferenças entre as experiências dos cardiopatas que necessitam de cirurgia de urgência e os que recebem preparação e planejamento. Uma especificidade a ser considerada é o fato de a pesquisadora trabalhar na instituição pesquisada, este aspecto consiste em um atravessamento importante da relação pesquisador-pesquisado tendo influenciado nas narrativas. Considera-se pertinente que os próximos estudos busquem compreender as vivências do pós-operatório tardio, de forma a investigar os efeitos da experiência cirúrgica na qualidade de vida e no tratamento, assim como as possíveis ressignificações existentes após o período de reabilitação.

Diante da compreensão de que os cardiopatas cirúrgicos vivenciam situações com importantes repercussões psicológicas e que se autorregulam através da relação ativa com as forças do meio em que se encontram, acredita-se que a oferta de um cuidado atento as necessidades dos pacientes por parte da equipe de saúde, potencializa a realização de ajustamentos criativos e, consequentemente, auxilia no atravessamento do processo cirúrgico propiciando a preservação da autenticidade. Desconsiderar os fatores psicológicos e emocionais pode prejudicar ou mesmo comprometer a evolução pós-operatória (Oliveira \& Lemos da Luz, 2009). Assim, quando os pacientes têm a possibilidade de experimentarem os próprios sentimentos e compreenderem os significados dessas manifestações, tendem a buscar na relação com o meio a melhor configuração possível para se manterem em equilíbrio saudável. Salienta-se a importância do incentivo constante ao protagonismo dos pacientes em relação ao tratamento ofertado, afinal, havendo o reconhecimento das necessidades para além dos aspectos biológicos, pode-se ofertar uma assistência mais integral e individualizada.

A Gestalt-terapia, por considerar a pessoa na sua relação com o mundo, contribui para uma visão integrada dessa população. A ênfase não está na doença, mas na relação que a pessoa estabelece com o adoecimento e o tratamento. A partir dessa perspectiva, o profissional de saúde faz parte desse meio e pode auxiliar no processo de responsabilização do indivíduo sobre o próprio projeto existencial. A pessoa consciente de si e do adoecer amplia as possibilidades, mesmo quando o meio proporciona poucas condições para as ações regulatórias acontecerem, estando hábil a responder de forma criativa a favor do próprio bem-estar.

\section{Referências}

Aguiar, L. (2014). Gestalt-terapia com crianças: teoria e prática. São Paulo: Summus, 2.

Ai, A. L., Peterson, C., Tice, T. N., Bolling, S. F. \& Koening, H. G. (2004). Faith-based and secular pathways to hope and optimistic subconstruct in middle-aged and older cardiac patients. Journal of Health Psychology, 9, 435-450.

Antony, S. M. (2009). Os ajustamentos criativos da criança em sofrimento: uma compreensão da gestalt-terapia sobre as principais psicopatologias da infância. Estudos e Pesquisas em Psicologia, 2, 356-375.

Banner, D. (2010). Becoming a coronary artery bypass graft surgery patient: a grounded theory study of women's experiences. Journal of Clinical Nursing, 19, $3123-3133$.

Banner, D., Miers, M., Clarke, B. \& Albarran, J. (2012). Women's experiences of undergoing coronary artery by-pass graft surgery. Journal of Advanced Nursing, 68, 919 - 930.

Bardin, L. (1977). Análise de conteúdo. Lisboa: Edições 70 Ltda.

Bardin, L. (2009). Análise de conteúdo. Lisboa: Edições 70.

Bergvik, S., Sorlie, T. \& Wynn, R. (2010). Approach and avoidance coping and regulatory focus in patients having coronary artery bypass surgery. Journal of Health Psychology, 15, 915 - 924. 
Cardoso, C. L. A. (2017). Saúde na ótica da gestalt-terapia [Resumo]. In: Congresso mineiro de gestalt-terapia: a prática clínica na contemporaneidade. Belo Horizonte.

Carné, S. (2002). Interfaces da clínica na prática psicomotora. In: Ferreira, C., Thompson, R., Mousinho, R. (Org.). Psicomotricidade clínica. São Paulo: Lovise.

Chiattone, H. B. C. \& Sebastiani, R. W. (1997). A ética em psicologia hospitalar. In: Angerami-Camon, V. A. (org). A Ética na Saúde. São Paulo: Pioneira.

Dórea, A. \& Lopes, A. A. B. A. (2010). Criança portadora de cardiopatia congênita e o trabalho do psicólogo na uti infantil. In: Ribeiro, A. L. A \& Gagliani, M. L. (org). Psicologia e Cardiologia: Um Desafio que Deu Certo: 1. Ed. São Paulo: Atheneu.

Dutra, C. M. P. \& Coelho, M. J. (2008). O tempo de cicatrização do coração: cuidar e os cuidados do cliente para superar as dificuldades após a cirurgia cardíaca. Enfermería global, 12, 1-7.

Erdmann, A. L., Lanzoni, G. M., Callegaro, G. D., Baggio, M. A. \& Koerich, C. (2013). Compreendendo o processo de viver significado por pacientes submetidos a cirurgia de revascularização do miocárdio. Revista Latino-Americana de Enfermagem, 21.

Figueiredo, J. O. \& Castro, E. E. C. (2015). Ajustamento criativo e estresse na hipertensão arterial sistêmica. Revista da Abordagem Gestáltica, 21, $37-46$.

Fontanella, B. J. B., Ricas, J. \& Turato, E. R. (2008). Amostragem por saturação em pesquisas qualitativas em saúde: contribuições teóricas. $\mathrm{Ca}$ dernos de Saúde Pública, 24, 17 - 27.

Frazão, L. M. (1992). A importância de compreender o sentido do sintoma em gestalt-terapia: contribuições da teoria de relação objetal. Revista de Gestalt, 2, 41-51.

Freitas, J. L., Stroiek, N. N. \& Botin, D. (2010). Gestalt-terapia e o diálogo psicológico no hospital: uma reflexão. Revista da Abordagem Gestáltica, $16,2,141-147$.

Ginger, S. \& Ginger, A. (1995). Gestalt: uma terapia do contato. São Paulo: Summus.

Hoffman, A., Oliveira, L. M. \& Massimi, M. (2014). Polifonias do Coração. São Paulo: FUMPEC.

Jung, C. G. (1978). Man and his symbols. London: Pan Book.
Lanzoni, G. M. M., Higashi, G. D., Koerich, C., Erdmann, A. L. \& Baggio, M. A. (2015). Processos que influenciam a maneira de viver a revascularização miocárdica. Texto e Contexto Enfermagem, 24, 270- 278.

Mello, F. \& Burd, M. (2004). Doença e família. São Paulo: Casa do Psicólogo.

Melo, V. R. (2007). O trauma psíquico no enfoque da neurociência e da gestalt-terapia (Monografia de Conclusão de Curso). Centro Universitário de Brasília, Brasília.

Minayo, M. C. S. (2008). O desafio do conhecimento. São Paulo: Hucitec.

Oliveira, M. F. \& Lemos da Luz, P. (2009). O impacto da cirurgia cardíaca. In: Filho, J. M. \& Burd, M. (Org.). Psicossomática hoje. Rio de Janeiro: Artmed, 253- 257.

Oliveira, S. A. \& Oliveira, M. F. P. (2010). Psicologia e Cardiologia: Um Desafio que Deu Certo. In: Ribeiro, A. L. A. \& Gagliani, M. L. (org). Psicologia e Cardiologia: Um Desafio que Deu Certo. São Paulo: Atheneu.

Parreiras, P. S. (2017). A gestalt-terapia em contexto hospitalar [Resumo]. In: Congresso mineiro de gestalt-terapia: a prática clínica na contemporaneidade. Belo Horizonte.

Perls, F. (1977b). Isto é gestalt. São Paulo: Summus.

Perls, F. (1988). A abordagem gestáltica e testemunha ocular da terapia. Rio de Janeiro: Editora JC.

Perls, F. (1997a). Gestalt-terapia explicada. São Paulo: Summus.

Perls, F., Hefferline, R. \& Goodman, P. (1997). Gestalt-terapia. São Paulo: Summus.

Polster E. \& Polster, M. (2001). Gestalt-terapia integrada. São Paulo: Summus.

Ribeiro, J. P. (1997). O ciclo do contato: temas básicos na abordagem gestáltica. São Paulo: Summus.

Ribeiro, J.P. (1994). Gestalt-terapia: o processo grupal. São Paulo: Summus.

Romano, B. W. (2001). Aspectos psicológicos e sua importância na cirurgia das coronárias. In: Romano, B. W. (org). Psicologia e Cardiologia: Encontros Possíveis. São Paulo: Casa do Psicólogo.

Roohafza, H., Sadeghi, M., Khani, A. Andalib, E., Alikhasi, H. \& Rafiel, M. (2015). Psychological state in patients undergoing coronary artery bypass grafting surgery or percutaneous coronary intervention and their spouses. International jornal of nursing practice, 21, 214-220. 
Rosário, C. A. \& Esch, C. F. (2014). Que negócio é esse de operar? - A abordagem gestáltica e o acompanhamento psicológico para a criança em processo cirúrgico. Revista IGT na Rede, 11 (21), 345-361.

Souza, J. M. \& Ribeiro, A. L. A. (2010). Tratamento cirúrgico das afecções da aorta e implicações psicológicas. In: Ribeiro, A. L. A; Gagliani, M. L. (org). Psicologia e Cardiologia: Um Desafio que Deu Certo. São Paulo: Atheneu.

Souza, R. H. S., Mantovani, M. F. \& Labronici, L. M. (2006). O vivido pelo paciente em pré-operatório de cirurgia cardíaca. Online Brazilian Journal Nursing, 5, 140-147.

Takiuti, M. E. et al. (2007). Qualidade de Vida após Revascularização Cirúrgica do Miocárdio, Angioplastia ou Tratamento Clínico. Arquivos Brasileiros de Cardiologia, 88, (5), 537-544.

Turato, E. R. (2011). Tratado da metodologia da pesquisa clínico-qualitativa: construção teórico-epistemológica, discussão comparada e aplicação nas áreas da saúde e humanas. Fortaleza: Vozes.

Wonttrich, S. H., Quintana, A. M., Camargo, V. P., Quadros, C. O. P., \& Naujorks, A. A. (2013). Significados e vivências mediante a indicação cirúrgica para pacientes cardíacos. Psicologia em Estudo, 18 (4), 609-619.
Wonttrich, S. H., Quintana, A. M., Moré, C. L., \& Oliveira, S. G. (2016). Significados da cirurgia cardíaca para pacientes submetidos ao processo cirúrgico. Interação em Psicologia, 20, 20-29.

Yontef, G. M. (1998). Processo, diálogo e awareness. São Paulo: Summus.

Carolina Soraggi Frez (ORCID 0000-0002-3587-1637), Universidade Federal de Minas Gerais. Endereço: Rua Progresso, 1260, apto 204 - Bairro Padre Eustáquio, Belo Horizonte, Minas Gerais. CEP: 30720320. Email: soraggi.carolina@gmail.com

Emma Elisa Carneiro de Castro (ORCID 0000-00034761-685X ), Universidade Federal de Minas Gerais. Email: emma.castro@terra.com.br

Recebido em 07.06.2019

Aceito em 08.10.2019 